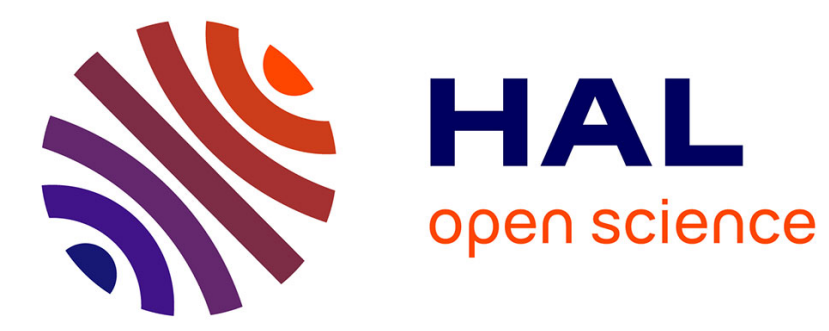

\title{
Damage creation in porous silicon irradiated by swift heavy ions
}

Bruno Canut, M. Massoud, Pascal Newby, Vladimir Lysenko, L. Frechette, Jean-Marie Bluet, I. Monnet

\section{- To cite this version:}

Bruno Canut, M. Massoud, Pascal Newby, Vladimir Lysenko, L. Frechette, et al.. Damage creation in porous silicon irradiated by swift heavy ions. Nuclear Instruments and Methods in Physics Research Section B: Beam Interactions with Materials and Atoms, 2014, 327, pp.99-102. 10.1016/j.nimb.2013.09.047 . hal-01490322

\section{HAL Id: hal-01490322 \\ https://hal.science/hal-01490322}

Submitted on 2 Jul 2021

HAL is a multi-disciplinary open access archive for the deposit and dissemination of scientific research documents, whether they are published or not. The documents may come from teaching and research institutions in France or abroad, or from public or private research centers.
L'archive ouverte pluridisciplinaire HAL, est destinée au dépôt et à la diffusion de documents scientifiques de niveau recherche, publiés ou non, émanant des établissements d'enseignement et de recherche français ou étrangers, des laboratoires publics ou privés. 


\title{
Damage creation in porous silicon irradiated by swift heavy ions
}

\author{
B. Canut ${ }^{\text {a,* }}$, M. Massoud ${ }^{\text {a }}$, P. Newby ${ }^{\text {b }}$, V. Lysenko ${ }^{\text {a }}$, L. Frechette ${ }^{\text {b }}$, J.M. Bluet ${ }^{\text {a }}$, I. Monnet ${ }^{\text {c }}$ \\ a Université de Lyon, Institut des Nanotechnologies de Lyon INL-IMR5270, CNRS, INSA de Lyon, Villeurbanne, F-69621 Villeurbanne, France \\ ${ }^{\mathrm{b}}$ Centre de Recherche en Nanofabrication et Nanocaractérisation (CNR2), Université de Sherbrooke, Sherbrooke, Québec, Canada \\ ${ }^{\mathrm{c}}$ Centre de Recherche sur les Ions, les Matériaux et la Photonique CIMAP-CIRIL, CEA-CNRS-ENSICAEN-Université de Caen, BP 513314070 Caen Cedex 5, France
}

\begin{abstract}
Mesoporous silicon (PS) samples were processed by anodising $\mathrm{p}^{+}$Si wafers in (1:1) HF-ethanol solution. Different current densities were used to obtain three different porosities (41\%,56\% and $75 \%)$. In all cases the morphology of the PS layer is columnar with a mean crystallite size between $12 \mathrm{~nm}$ (75\% porosity) and $19 \mathrm{~nm}$ (41\% porosity). These targets were irradiated at the GANIL accelerator, using different projectiles $\left({ }^{130} \mathrm{Xe}\right.$ ions of $91 \mathrm{MeV}$ and $29 \mathrm{MeV},{ }^{238} \mathrm{U}$ ions of $110 \mathrm{MeV}$ and $\left.850 \mathrm{MeV}\right)$ in order to vary the incident electronic stopping power $S_{\mathrm{e}}$. The fluences ranged between $10^{11}$ and $7 \times 10^{13} \mathrm{~cm}^{-2}$. Raman spectroscopy and cross sectional SEM observations evidenced damage creation in the irradiated nanocrystallites, without any degradation of the PS layer morphology at fluences below $3 \times 10^{12} \mathrm{~cm}^{-2}$. For higher doses, the columnar morphology transforms into a spongy-like structure. The damage cross sections, extracted from Raman results, increase with the electronic stopping power and with the sample porosity. At the highest $S_{\mathrm{e}}\left(>10 \mathrm{keV} \mathrm{nm}^{-1}\right)$ and the highest porosity (75\%), the track diameter coincides with the crystallite diameter, indicating that a single projectile impact induces the crystallite amorphization along the major part of the ion path. These results were interpreted in the framework of the thermal spike model, taking into account the low thermal conductivity of the PS samples in comparison with that of bulk silicon.
\end{abstract}

\section{Introduction}

It is well established that single crystalline silicon irradiated with monoatomic heavy ions accelerated in the $\mathrm{GeV}$ range cannot be damaged via electronic processes. Many experiments, conducted on high energy accelerators at the highest electronic stopping powers $\left(S_{\mathrm{e}}\right)$ available (i.e. $\approx 25 \mathrm{keV} \mathrm{nm}^{-1}$ with ${ }^{238} \mathrm{U}$ ions of $1 \mathrm{GeV}$ ), evidenced that the radiation-induced disorder in bulk $\mathrm{Si}$ is only due to nuclear collisions and thus occurs at the end of range of the projectiles [1,2]. Amorphous latent tracks in Si single crystals have been only registered when using $C_{60}$ clusters as projectiles $[3,4]$. The insensitivity of bulk Si to irradiation in the electronic regime can be mainly ascribed to its rather high thermal diffusivity $\left(D=0.9 \mathrm{~cm}^{2} \mathrm{~s}^{-1}\right)$. According to the thermal spike model $[5,6]$, the prompt energy received by the target electrons after the passage of the projectile $\left(10^{-17}\right.$ s per unit cell $)$ gives rise to a local thermalization of the electron gas within a period of $\approx 10^{-15} \mathrm{~s}$. This step is followed by an electron-phonon coupling, causing a local temperature increase (thermal spike). For a few $10^{-12} \mathrm{~s}$, a molten phase develops around the ion path and produces the so-called track after ultrafast quenching. Such a scenario does not occur in materials having a high thermal conductivity, like metals and

\footnotetext{
* Corresponding author. Tel.: +33 4724387 34; fax: +33 472438531 .

E-mail address: bruno.canut@insa-lyon.fr (B. Canut).
}

semiconductors, as the lattice temperature cannot reach the melting temperature. The situation should be completely different in PS samples whose thermal diffusivity is by two orders of magnitude lower than that of bulk Si. The aim of this work is to investigate the "response" of such targets to ion irradiation dominated by electronic slowing-down processes.

\section{Experimental procedure}

The porous silicon samples were processed by electrochemical etching of $\mathrm{p}^{+}(\rho \approx 0.01 \Omega \mathrm{cm})$ monocrystalline (100) Si wafers. This was carried out in a Teflon cell, using a (1:1) HF-ethanol mixture. In order to improve uniformity of the PS layers, we used a pulsed current with a minimum value set at zero to stop periodically the etching process [7]. Different anodisation current densities were used to obtain three different porosities: $41 \%, 56 \%$ and $75 \%$. These values were measured by infrared reflectivity using the Landau-Lifshitz-Looyenga effective medium model [8]. In all cases the thickness of the porous layer was about $25 \mu \mathrm{m}$. PS samples elaborated in these conditions are mesoporous and consist of dendritic silicon quasi-columns with mean diameters of $19 \pm 1 \mathrm{~nm}$, $16 \pm 1 \mathrm{~nm}$ and $12 \pm 1 \mathrm{~nm}$ for $41 \%, 56 \%$ and $75 \%$ porosities, respectively [9]. These quasi-columns remain monocrystalline and retain the crystallographic orientation of the substrate. The PS targets were irradiated at the SME and IRRSUD beamlines of the GANIL 
accelerator [10], using ${ }^{130} \mathrm{Xe}$ ions (91 MeV and $29 \mathrm{MeV}$ energies) or ${ }^{238} \mathrm{U}$ ions ( $110 \mathrm{MeV}$ and $850 \mathrm{MeV}$ energies). The fluences ranged from $10^{12}$ to $7 \times 10^{13} \mathrm{~cm}^{-2}$. All the irradiations were performed at room temperature at quasi normal beam incidence with a flux limited to $10^{9} \mathrm{~cm}^{-2} \mathrm{~s}^{-1}$ in order to avoid any overheating of the targets. The targets were intentionally tilted by a few degrees in respect with the beam direction in order to exclude any channeling effect of the incoming projectiles. The main irradiation parameters, calculated from the SRIM2013 code [11], are listed in Table 1. The chosen target density was that of bulk $\mathrm{Si}\left(\rho_{\mathrm{Si}}=2.33 \mathrm{~g} \mathrm{~cm}^{-3}\right)$ as the expected damage creation process in PS targets will be governed by the projectile slowing-down along the quasi columnar crystallites whose density is equal to $\rho_{\mathrm{Si}}$ whatever the porosity. The nuclear damage cross-sections $A_{\mathrm{n}}$ indicated in the last column of Table 1 correspond to elastic displacements induced per one incident projectile at the target surface. They were calculated assuming a displacement energy of $21 \mathrm{eV}$ [12] for silicon atoms. The radiation-induced disorder within the PS layers was evidenced by Raman spectroscopy, using a Renishaw RM 1000 spectrometer operating at a laser wavelength of $532 \mathrm{~nm}$. The morphology of the samples was studied by scanning electron microscopy (SEM) imaging performed on the target cross-section.

\section{Results and discussion}

Fig. 1 shows the fluence evolution of the Raman spectra recorded on $56 \%$ porosity PS targets irradiated with ${ }^{238} \mathrm{U}$ ions of $110 \mathrm{MeV}$ energy. The spectrum related to the pristine target exhibits an unique sharp peak centered near $521 \mathrm{~cm}^{-1}$ which is characteristic of bulk crystalline Si [13]. Compared to the Raman peak which would be obtained in bulk c-Si, the peak recorded in pristine PS is shifted by a few $\mathrm{cm}^{-1}$ and asymmetrically broadened, both towards lower energies. These changes are usually ascribed to phonon confinement [14]. As the irradiation fluence increases, one evidences an additional large peak centered at $480 \mathrm{~cm}^{-1}$ which can be related to the transverse optical branch of a-Si [15]. Concomitantly, the c-Si peak gradually disappears. These features show that ion irradiation causes the amorphization of porous silicon. Transmission electron microscopy observations are planned in a future work to confirm this structural change. Taking into account the laser wavelength $(532 \mathrm{~nm})$ used in the present work, the absorption coefficient of $\mathrm{Si}$ is about $\alpha \approx 7 \times 10^{3} \mathrm{~cm}^{-1}$ [16] and thus the maximum depth probed by the analysis does not exceed $2 / \alpha \approx 3 \mu \mathrm{m}$. In these first micrometers below the target surface, the inelastic slowing-down processes dominate the elastic ones by three orders of magnitude (see Table 1) and the atomic displacements via collisional effects can be considered as negligible. Consequently, the radiation-induced disorder evidenced by Raman spectroscopy in mesoporous silicon is necessarily ascribable to the high density of electronic excitations deposited in the crystallites. In order to determine the amorphous fraction $\rho_{\mathrm{a}}$ in irradiated PS targets, we have fitted each Raman spectrum with four Gaussian functions. The first one, centered at $480 \mathrm{~cm}^{-1}$, corresponds to the amorphous contribution. The second one, centered at $520 \mathrm{~cm}^{-1}$, corresponds to the c-Si peak. The two last ones, with free maxima

Table 1

Main features of the ion irradiations in Si: incident energy $(E)$, projected range $\left(R_{\mathrm{p}}\right)$, electronic $\left(S_{\mathrm{e}}\right)$ and nuclear $\left(S_{\mathrm{n}}\right)$ stopping powers. $A_{\mathrm{n}}$ is the cross-section for disordering the target surface via elastic processes (see text).

\begin{tabular}{lcccll}
\hline Projectile & $E(\mathrm{MeV})$ & $R_{\mathrm{p}}(\mu \mathrm{m})$ & $S_{\mathrm{e}}\left(\mathrm{keV} \mathrm{nm}^{-1}\right)$ & $S_{\mathrm{n}}\left(\mathrm{keV} \mathrm{nm}^{-1}\right)$ & $A_{\mathrm{n}}\left(\mathrm{nm}^{2}\right)$ \\
\hline${ }^{130} \mathrm{Xe}$ & 29 & 6.8 & 6.4 & 0.24 & 0.032 \\
${ }^{130} \mathrm{Xe}$ & 91 & 13.7 & 10.9 & 0.10 & 0.012 \\
${ }^{238} \mathrm{U}$ & 110 & 14.2 & 12.3 & 0.35 & 0.040 \\
${ }^{238} \mathrm{U}$ & 850 & 47.6 & 27.0 & 0.07 & 0.008 \\
\hline
\end{tabular}

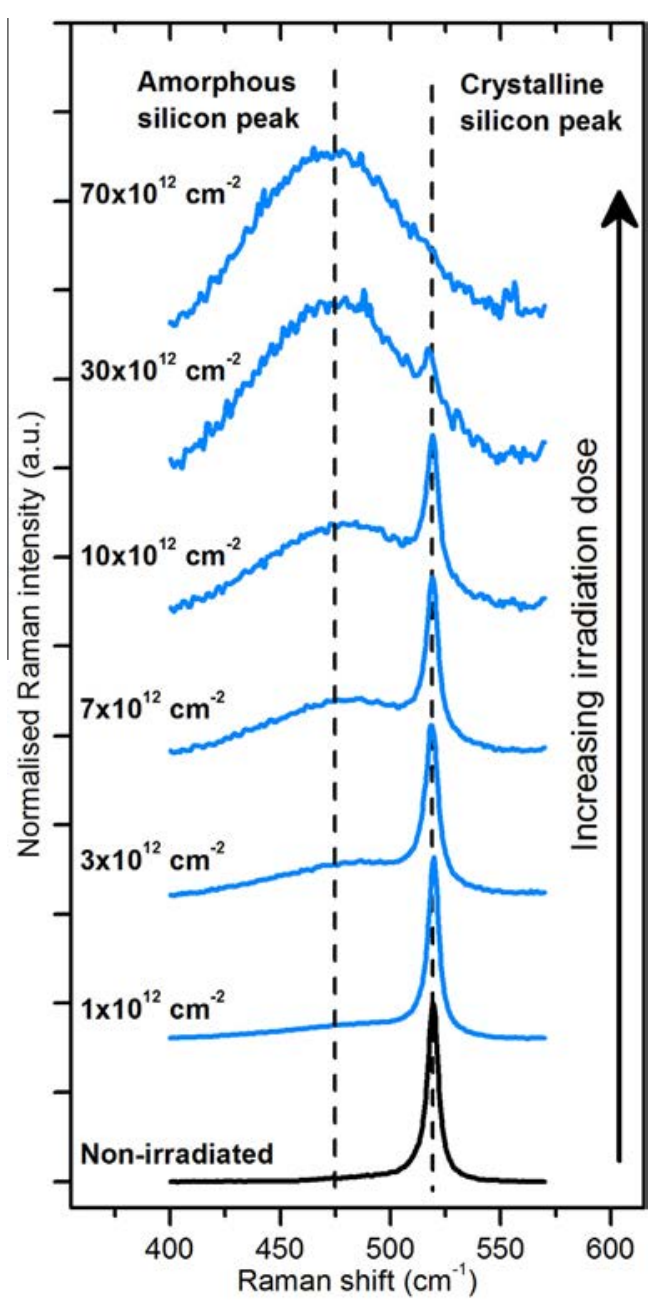

Fig. 1. Fluence evolution of the Raman spectra recorded on $56 \%$ porosity PS targets irradiated with ${ }^{238} \mathrm{U}$ ions of $110 \mathrm{MeV}$ energy. Each spectrum is normalized to the intensity of its highest peak.

located between 420 and $520 \mathrm{~cm}^{-1}$, account for the asymmetry of the pristine PS peak mentioned above. We analyzed the area $I_{\mathrm{a}}$ of the amorphous peak and compared it to the area $I$ of the entire Raman spectrum extending from 400 to $550 \mathrm{~cm}^{-1}$. The amorphous fraction $\rho_{\mathrm{a}}$ was then calculated from the ratio:

$\rho_{\mathrm{a}}=\frac{I_{\mathrm{a}}}{I}$

Note that this procedure assumes that the Raman cross-sections of the amorphous and crystalline signals are identical [17]. Fig. 2 displays, for the different studied porosities, the fluence evolution of $\rho_{\mathrm{a}}$ in PS targets irradiated with ${ }^{238} \mathrm{U}$ ions of $110 \mathrm{MeV}$ energy. In the three cases, the damage kinetics were fitted using a Poisson's law:

$\rho_{\mathrm{a}}=1-\exp \left(-A_{\mathrm{d}} \cdot \Phi\right)$,

where $\Phi$ is the fluence and $A_{\mathrm{d}}$ is the amorphization cross-section. Although not entirely satisfactory to account for the experimental data at all fluences, these fittings allowed to extract the following values for $A_{\mathrm{d}}$ : $14 \mathrm{~nm}^{2}, 26 \mathrm{~nm}^{2}$ and $95 \mathrm{~nm}^{2}$ for $41 \%, 56 \%$ and $75 \%$ porosities, respectively. Such damage cross-sections exceed by three orders of magnitude the cross-sections $A_{\mathrm{n}}$ for displacement events via nuclear processes reported in Table 1 . This confirms that the disorder creation in PS targets is necessarily due to the electronic slowing-down of the projectiles. The increase of $A_{\mathrm{d}}$ with the porosity $P$ can be ascribed to the thermal conductivity $K_{\mathrm{PS}}$ of 


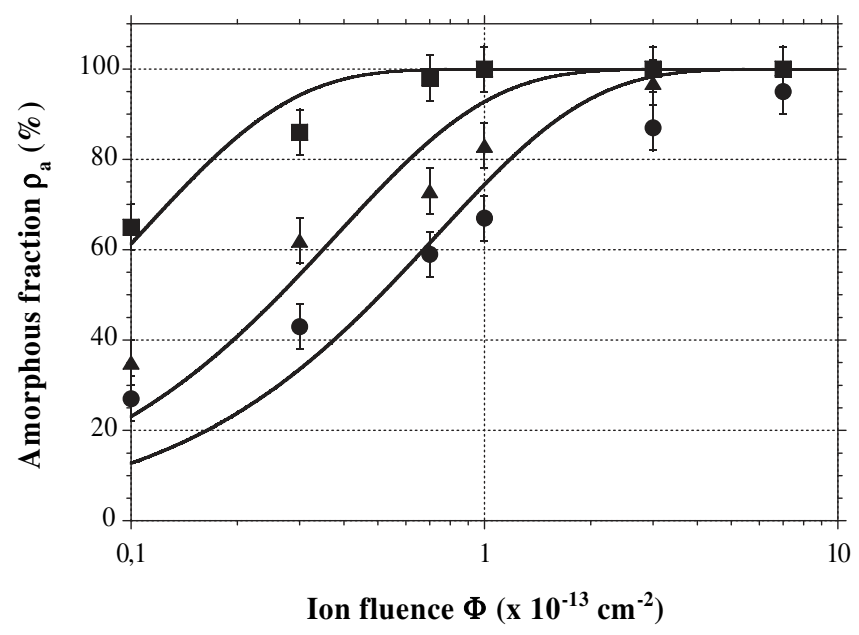

Fig. 2. Amorphous fraction ( $\rho_{\mathrm{a}}$ ) versus the fluence of PS targets irradiated with ${ }^{238} \mathrm{U}$ ions of $110 \mathrm{MeV}$ energy. Three different porosities were used: $41 \%$ (circles), 56\% (triangles) and $75 \%$ (squares). The continuous curves are the best fits of the data using a Poisson's law (see text).

the mesoporous target which, in the case of a columnar morphology, decreases with P according to the following relation [18]:
$K_{\mathrm{PS}}=\frac{K_{\mathrm{Si}}}{1+\frac{4 \Lambda_{\mathrm{Si}}}{3 d_{\mathrm{cr}}}}(1-P)^{3}$,

where $K_{\mathrm{Si}}$ is the thermal conductivity of bulk $\mathrm{Si}$ $\left(K_{\mathrm{Si}}=150 \mathrm{~W} \mathrm{~m}^{-1} \mathrm{~K}^{-1}\right), \Lambda_{\mathrm{Si}}$ is the phonon mean free path in single crystalline $\mathrm{Si}$ ( $\Lambda_{\mathrm{Si}}=43 \mathrm{~nm}$ at room temperature) and $d_{\mathrm{cr}}$ is the mean size of the nanocrystallites. The obtained values $\left(K_{\mathrm{PS}}=7.7 \mathrm{~W} \mathrm{~m}^{-1} \mathrm{~K}^{-1}, \quad 2.8 \mathrm{~W} \mathrm{~m}^{-1} \mathrm{~K}^{-1}\right.$ and $0.4 \mathrm{~W} \mathrm{~m}^{-1} \mathrm{~K}^{-1}$ for $P=41 \%, 56 \%$ and $75 \%$, respectively) are by two orders of magnitude lower than $K_{\mathrm{Si}}$. In these conditions and according to the thermal spike model, the target temperature after electron-phonon coupling should reach the melting temperature thus inducing amorphous track formation along the projectile path. It is worthwhile to notice that in the case of the highest porosity (75\%), the damage cross-section corresponds to a track diameter $d_{\mathrm{tr}}=11 \mathrm{~nm}$ $\left(A_{\mathrm{d}}=\pi d_{\mathrm{tr}}^{2} / 4\right)$ which is very close to the crystallite size $\left(d_{\mathrm{cr}}=12 \mathrm{~nm}\right.$ for $P=75 \%$ ). This indicates that only one projectile impact onto the crystallite is sufficient to amorphize it entirely in the first micrometers below the surface.

In order to depict morphological changes of the PS targets after irradiation, cross-section SEM observations were performed at different fluences. Fig. 3 presents the images obtained on samples of $56 \%$ and $75 \%$ porosities irradiated with ${ }^{238} \mathrm{U}$ ions of $110 \mathrm{MeV}$ energy. Up to high levels of amorphization $\left(\rho_{\mathrm{a}} \approx 70-80 \%\right)$, the structure of the target is not significantly modified. At the highest

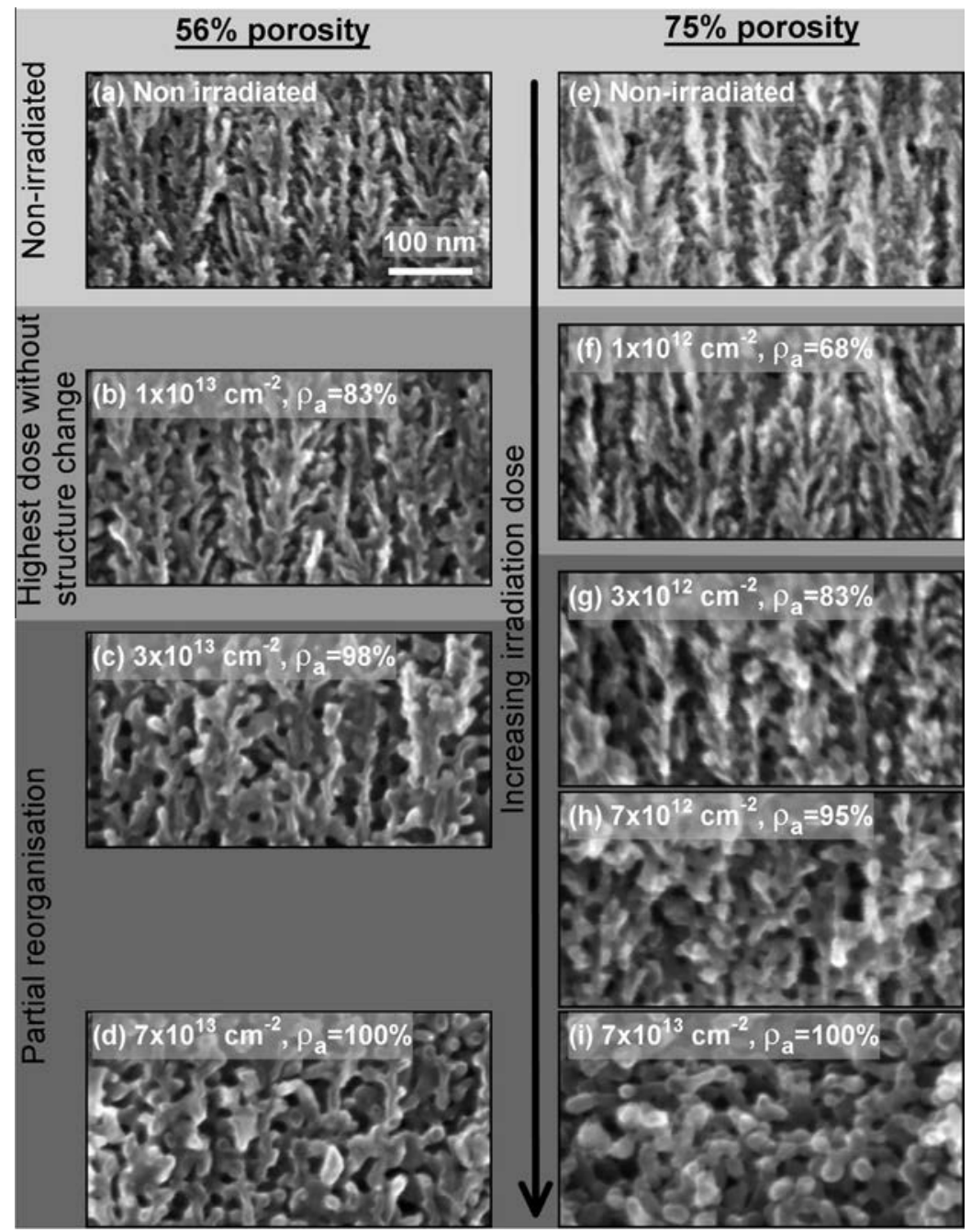

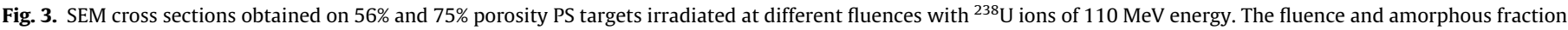
$\left(\rho_{\mathrm{a}}\right)$ are indicated on each image and all images are recorded at the same magnification. 


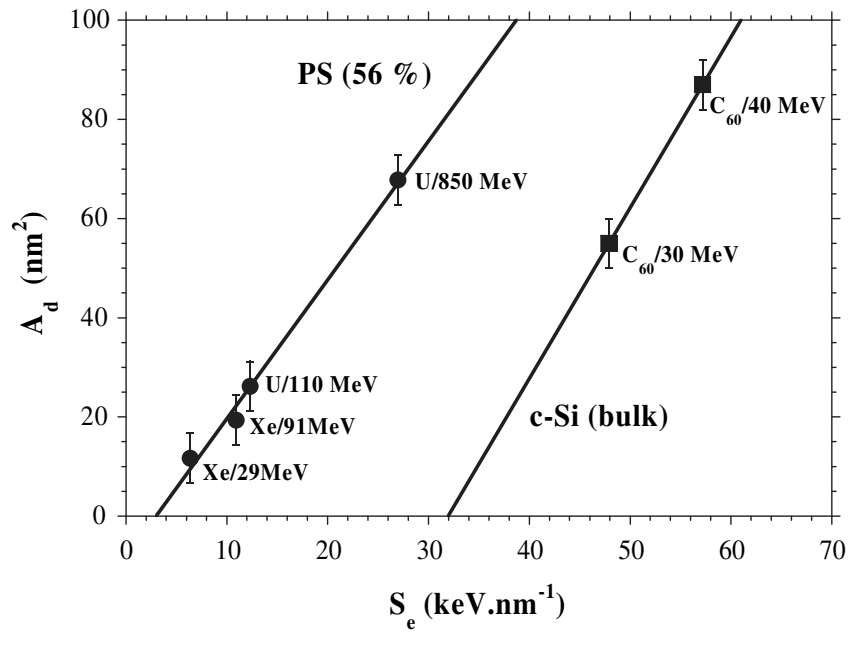

Fig. 4. Damage cross-sections $\left(A_{\mathrm{d}}\right)$ versus the incident electronic stopping power $\left(S_{\mathrm{e}}\right)$ for $56 \%$ porosity PS targets (circles). Previous results obtained in bulk $\mathrm{Si}$ irradiated with $\mathrm{C}_{60}$ clusters (squares) are also given for comparison. In both cases, the continuous straight lines are the best fits to the data.

fluences $\left(\Phi>3 \times 10^{13} \mathrm{~cm}^{-2}\right.$ for $56 \%$ porosity and $\Phi>3 \times 10^{12}$ $\mathrm{cm}^{-2}$ for $75 \%$ porosity), where $\rho_{\mathrm{a}}$ exceeds $85 \%$, a coarsening of the PS structure is evidenced and the columnar morphology vanishes. However, the samples remain porous even at $100 \%$ amorphization. Different images, recorded at different depth from the surface, showed that this structural evolution takes place throughout the major part of the PS layer thickness. It is interesting to notice that the "response" of porous silicon irradiated in the electronic regime is completely different from that obtained in the nuclear regime $(E<0.1 \mathrm{MeV}$ per mass unit). In this latter case, it was shown that collisional processes induce a densification of the porous layer [19].

From Raman spectroscopy and its quantitative exploitation described above, the damage cross-sections were measured for the different target porosities and irradiation conditions used in this work. The evolution of $A_{\mathrm{d}}$ versus the electronic stopping power $S_{\mathrm{e}}$ for a target of medium porosity (56\%) is plotted in Fig. 4. A linear fitting of the data intercepts the horizontal axis at $S_{\text {eth }}$ $\approx 3 \mathrm{keV} \mathrm{nm}^{-1}$. Within the experimental errors and by neglecting the possible influence of the different projectile velocities, this value may be regarded as the threshold for damage creation in PS of $56 \%$ porosity irradiated in the electronic regime. As a comparison, from $\mathrm{C}_{60}$ bombardment in the $10 \mathrm{MeV}$ range, a much higher threshold $S_{\text {eth }} \approx 32 \mathrm{keV} \mathrm{nm}^{-1}$ was estimated in bulk single crystalline Si [3]. The low threshold evidenced in the studied targets, which is comparable to that obtained in some insulating materials like $\mathrm{SiO}_{2}[20]$ and $\mathrm{LiNbO}_{3}$ [21], confirms the increased sensitivity of columnar porous silicon submitted to irradiation in the electronic stopping power regime.

\section{Conclusion}

In this work, we have shown that columnar porous silicon can be amorphized by swift heavy ion irradiation. This result, which cannot be obtained in bulk single crystalline silicon irradiated at comparable electronic stopping powers, was ascribed to the low thermal conductivity of the PS target. A more quantitative interpretation of the present results is now required. For this purpose, we plan to apply the thermal spike modeling in its three dimensional version [22] to account for the radial inhomogeneity of this porous material in the amorphous track formation.

\section{References}

[1] M. Levalois, P. Bogdanski, M. Toulemonde, Nucl. Instrum. Methods B 63 (1992) 14.

[2] P. Mary, P. Bogdanski, M. Toulemonde, R. Spohr, J. Vetter, Nucl. Instrum. Methods B 62 (1992) 391.

[3] B. Canut, N. Bonardi, S.M.M. Ramos, S. Della-Negra, Nucl. Instrum Methods B 146 (1998) 296.

[4] A. Dunlop, G. Jaskierowicz, S. Della-Negra, Nucl. Instrum. Methods B 146 (1998) 302.

[5] C. Dufour, A. Audouard, F. Beuneu, J. Dural, J.P. Girard, A. Hairie, M. Levalois, E. Paumier, M. Toulemonde, J. Phys.: Condens. Matter 5 (1993) 4573.

[6] C. Dufour, F. Beuneu, E. Paumier, M. Toulemonde, Europhys. Lett. 45 (1999) 585.

[7] S. Billat, M. Thönissen, R. Arens-Fischer, M.G. Berger, M. Krüger, H. Lüth, Thin Solid Films 297 (1997) 22.

[8] V. Lysenko, F. Bidault, S. Alekseev, V. Zaitsev, D. Barbier, C. Turpin, F. Geobaldo, P. Rivolo, E. Garrone, J. Phys. Chem. B 109 (2005) 19711.

[9] P. Chantrenne, V. Lysenko, Phys. Rev. B. 72 (2005) 035318.

[10] Grand Accélérateur National d'Ions Lourds, Bd Henri Becquerel, BP 55027 14076 CAEN Cedex, France.

[11] J.F. Ziegler, J.P. Biersack, U. Littmark, Stopping Power and Ranges of Ions in Matter, vol. I, Pergamon Press, New York, 1985.

[12] J. Bourgoin, M. Lannoo, Point Defects in Semiconductors, vol. I, Springer, Berlin, 1983.

[13] H. Richter, Z.P. Wang, L. Ley, Solid State Commun. 39 (1981) 625.

[14] I.H. Campbell, P.M. Fauchet, Solid State Commun. 58 (1986) 739.

[15] J.E. Smith Jr, M.H. Brodsky, B.L. Crowder, M.I. Nathan, Phys. Rev. Lett. 26 (1971) 642.

[16] M.A. Green, M.J. Keevers, Prog. Photovoltaics Res. Appl. 3 (1995) 189.

[17] E. Vallat-Sauvain, C. Droz, F. Meillaud, J. Bailat, A. Shah, C. Ballif, J. Non-Cryst. Solids 352 (2006) 1200.

[18] V. Lysenko, S. Perichon, B. Remaki, D. Barbier, B. Champagnon, J. Appl. Phys. 86 (1999) 6841.

[19] A. Simon, F. Paszti, A. Manuaba, A.Z. Kiss, Nucl. Instrum. Methods B 158 (1999) 658.

[20] A. Meftah, F. Brisard, J.M. Costantini, E. Dooryhee, M. Hage-Ali, M. Hervieu, J.P. Stoquert, F. Studer, M. Toulemonde, Phys. Rev. B 49 (1994) 12457.

[21] B. Canut, S. Ramos, N. Bonardi, J. Chaumont, H. Bernas, E. Cottereau, Nucl. Instrum. Methods B 122 (1997) 335.

[22] Ch. Dufour, V. Khomenkov, G. Rizza, M. Toulemonde, J. Phys. D: Appl. Phys. 45 (2012) 065302. 